\title{
Internally Simulated Movement Sensations during Motor Imagery Activate Cortical Motor Areas and the Cerebellum
}

\author{
Eiichi Naito, ${ }^{1}$ Takanori Kochiyama, ${ }^{2}$ Ryo Kitada, ${ }^{2}$ Satoshi Nakamura, ${ }^{3}$ Michikazu Matsumura, ${ }^{1,2}$ \\ Yoshiharu Yonekura, ${ }^{3}$ and Norihiro Sadato ${ }^{4}$ \\ ${ }^{1}$ Faculty of Human Studies and ${ }^{2}$ Graduate School of Human and Environmental Studies, Kyoto University, Sakyo-ku \\ Kyoto 606-8501, Japan, 3Biomedical Imaging Research Center, Fukui Medical School, Fukui 910-1193, Japan, and \\ ${ }^{4}$ Department of Cerebral Research, National Institute for Physiological Sciences, Okazaki Aichi 444-8585, Japan
}

It has been proposed that motor imagery contains an element of sensory experiences (kinesthetic sensations), which is a substitute for the sensory feedback that would normally arise from the overt action. No evidence has been provided about whether kinesthetic sensation is centrally simulated during motor imagery. We psychophysically tested whether motor imagery of palmar flexion or dorsiflexion of the right wrist would influence the sensation of illusory palmar flexion elicited by tendon vibration. We also tested whether motor imagery of wrist movement shared the same neural substrates involving the illusory sensation elicited by the peripheral stimuli.

Regional cerebral blood flow was measured with $\mathrm{H}_{2}{ }^{15} \mathrm{O}$ and positron emission tomography in 10 right-handed subjects. The right tendon of the wrist extensor was vibrated at $83 \mathrm{~Hz}$ ("illusion") or at $12.5 \mathrm{~Hz}$ with no illusion ("vibration"). Subjects imagined doing wrist movements of alternating palmar and dorsiflexion at the same speed with the experienced illusory movements ("imagery"). A "rest" condition with eyes closed was included. We identified common active fields between the contrasts of imagery versus rest and illusion versus vibration.

Motor imagery of palmar flexion psychophysically enhanced the experienced illusory angles of plamar flexion, whereas dorsiflexion imagery reduced it in the absence of overt movement. Motor imagery and the illusory sensation commonly activated the contralateral cingulate motor areas, supplementary motor area, dorsal premotor cortex, and ipsilateral cerebellum. We conclude that kinesthetic sensation associated with imagined movement is internally simulated during motor imagery by recruiting multiple motor areas.

Key words: positron emission tomography; PET; motor imagery; kinesthetic illusion; wrist movement; cingulate motor area; CMA; supplementary motor area; SMA; dorsal premotor cortex; $P M D$; cerebellum
Many studies have shown that cortical motor areas, parietal cortices, and the cerebellum, which are normally engaged in the actual execution of movements (Ehrsson et al., 2000), are the main neural substrates for various types of motor imagery (Roland et al., 1980; Decety et al., 1990; Stephan et al., 1995; Porro et al., 1996; Roth et al., 1996; Sirigu et al., 1996; Jueptner et al., 1997; Luft et al., 1998; Lotze et al., 1999; Binkofski et al., 2000; Gerardin et al., 2000; Thobois et al., 2000). Therefore, motor imagery is generally considered to be a neural process of mental rehearsal (simulation) of movement, including motor planning.

It is empirically known that many people can experience vivid motor imagery, mostly involving a kinesthetic representation of actions (Feltz and Landers, 1983; Mahoney and Avener, 1987; Jeannerod, 1994). It has been proposed that motor imagery may contain an element of sensory experiences (kinesthetic sensations), which are a substitute for the sensory feedback that would normally arise from an overt action by accessing memories of previous enactments (Annett, 1996). However, no evidence has

\footnotetext{
Received Sept. 28, 2001; revised Jan. 16, 2002; accepted Jan. 18, 2002.

This study was supported by the Hayao Nakayama Scientific Foundation and a research grant from the Ministry of Education of Japan. This study was supported in part by a research grant from the "Research for the Future" Program of the Japan Society for the Promotion of Science (JSPS-RFTF97L00203). We thank Katsuya Sugimoto for his technical support.

Correspondence should be addressed to Dr. Norihiro Sadato, Department of Cerebral Research, National Institute for Physiological Sciences, Okazaki, Aichi 444-8585, Japan. E-mail: sadato@nips.ac.jp.

Copyright (C) 2002 Society for Neuroscience $\quad 0270-6474 / 02 / 223683-09 \$ 15.00 / 0$
}

been provided about whether such sensory experiences are centrally simulated during motor imagery. It is hypothesized that subjects internally simulate kinesthetic sensation associated with imagined movement during motor imagery.

To test this hypothesis, an illusory limb movement could be used to evaluate the component of kinesthetic sensation during motor imagery of the same limb movement, because subjects experience movement sensation during illusion, and the sensation is passively elicited by peripheral vibration stimuli without any mental simulation (Goodwin et al., 1972a,b; Craske, 1977; Naito et al., 1999; Naito and Ehrsson, 2001). At first, we psychophysically evaluated the effect of motor imagery, during which subjects imagined doing palmar flexion or dorsiflexion of the right wrist, on the illusory palmar flexion of the wrist; we expect that motor imagery directionally influences illusory experiences.

If so, some brain regions involving the motor imagery of wrist movements would be commonly shared by the illusory wrist movement. We can assume that these common regions would be motor-related areas and that they would most probably engage internal simulation of kinesthetic sensation during motor imagery, because the supplementary motor area (SMA), cingulate motor area (CMA), dorsal premotor cortex (PMD) (Roland et al., 1980; Stephan et al., 1995; Lotze et al., 1999; Binkofski et al., 2000; Gerardin et al., 2000; Thobois et al., 2000), and primary sensorimotor cortices (SM1) (Porro et al., 1996; Roth et al., 1996; Gerardin et al., 2000; Thobois et al., 2000), of which involvement in motor imagery has been shown, are significantly active when 
subjects experience illusory sensation of limb movements (Naito et al., 1999; Naito and Ehrsson, 2001). In addition, kinesthetic illusory wrist movement activated these motor areas that are active during actual wrist movements (Naito and Ehrsson, 2001). We used both motor imagery and kinesthetic illusion of right wrist movements and measured regional cerebral blood flow (rCBF) with positron emission tomography (PET).

\section{MATERIALS AND METHODS}

The study was approved by the Ethics Committee of Fukui Medical University and was performed according to the principles and guidelines of the Declaration of Helsinki, 1975. All subjects gave their written informed consent.

\section{Psychophysical experiment}

Evaluation of subject's motor imagery ability. The subjects were 19 healthy right-handed men, age 18-22 years. Before the experiment, we used the controllability of motor imagery (CMI) test to evaluate their ability to regenerate and manipulate the imagined postures of their body parts in response to verbal instructions for movement of sequential body parts (arm, leg, torso, head) (Naito, 1994). The CMI test is composed of 15 sets of trials. One trial consists of six consecutive instructions. With eyes closed, subjects are required to imagine that they are moving their body parts according to the verbal instructions. When they imagine, no actual movement is permitted. Each instruction is given every $3 \mathrm{sec}$. Starting from the basic posture (instruction 1), subjects move only one body part per instruction. Immediately after six instructions are completed, subjects have to show the final posture that they have in their mind by actually performing it. The experimenter can give a score only when entire body configuration is correct, and hence the full score after all questions is 15 . The validity and reliability of this test were carefully evaluated by Nishida et al. (1986). As shown by Nishida et al. (1986) and Naito (1994), gymnasts and subjects doing sports (football, volleyball, etc.), who are generally good at imagining their body parts, showed higher scores when compared with subjects who did not do any sport.

Angle evaluation task. The subjects lay comfortably on a bed in a supine position, with their eyes closed and the right forearm resting horizontally on the bed. The right wrist protruded from the bed and hung freely without touching anything (Fig. 1a). The wrist was completely relaxed throughout the experiment. The mean angle of natural palmar flexion was $45^{\circ}$ during relaxation (see Fig. $1 a$, ang). We first tested the accuracy with which the subjects could evaluate and regenerate passively flexed wrist angles. From the relaxed position, the wrist was passively flexed palmarly toward the tested angles and passively returned to the original position. The tested angles ranged from 5 to $25^{\circ}$, with increments of $2.5^{\circ}$ (Clark et al., 1985). Immediately afterward, the subjects were required to replicate the perceived flexed angles as precisely as possible by voluntarily flexing the wrist. We measured the wrist angles from the original position with the aid of two small bars attached laterally to the surface of the skin over the wrist. The angle of these bars was read on a transparent protractor, which was placed adjacent to the wrist (Fig. 1a) (Kitada et al., 2002). The order of tested angles was randomized, and each subject performed 12 trials. Although the subjects tended to underestimate the passively flexed angles, there was a significant correlation between the tested angles and the performed angles (Fig. 1b).

Examination of the motor imagery effect on kinesthetic sensation. The right wrist was stimulated with a vibrator (Sasuri-Vib EV258-A, Matsushita Electronics, Osaka, Japan) at $83 \mathrm{~Hz}$ with an amplitude of $\sim 2 \mathrm{~mm}$. The vibration site, $\sim 1 \mathrm{~cm}^{2}$, was marked on the surface of the skin over the wrist extensor tendons. The experimenter vibrated the site as precisely and constantly as possible with slight pressure on it. The duration of vibration was $55.0 \mathrm{sec}$, and there was a pretest period of $5.0 \mathrm{sec}$ before the vibration. The $55.0 \mathrm{sec}$ were divided into three periods: $15.0 \mathrm{sec}$ $(5.0-20.0 \mathrm{sec}), 25.0 \mathrm{sec}(20.0-45.0 \mathrm{sec})$, and $15.0 \mathrm{sec}(45.0-60.0 \mathrm{sec})$ (see Fig. $2 a$ ). The subjects were informed verbally of the onset of each period. In a control condition, subjects received vibratory stimuli eliciting illusory wrist movements without any motor imagery. The subjects had to recall the maximum illusory wrist angle experienced for each of the three vibration periods. The subjects said "start" when they felt an illusory movement of the wrist begin and "stop" when the sense of movement disappeared. The start time and duration of the illusion were calculated from these responses. After the vibration, the subjects reported three illusory angles corresponding to each vibration period by actually moving

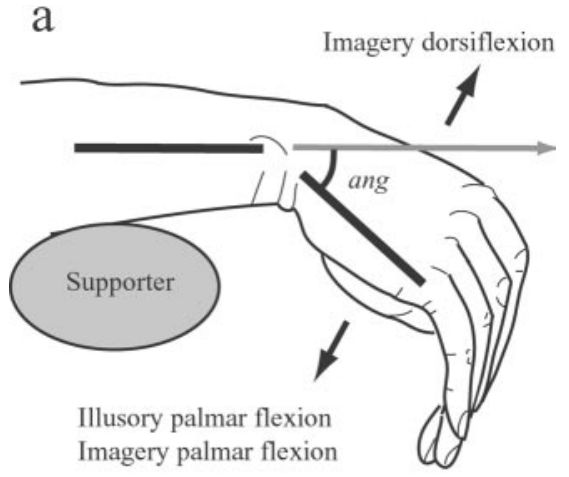

b

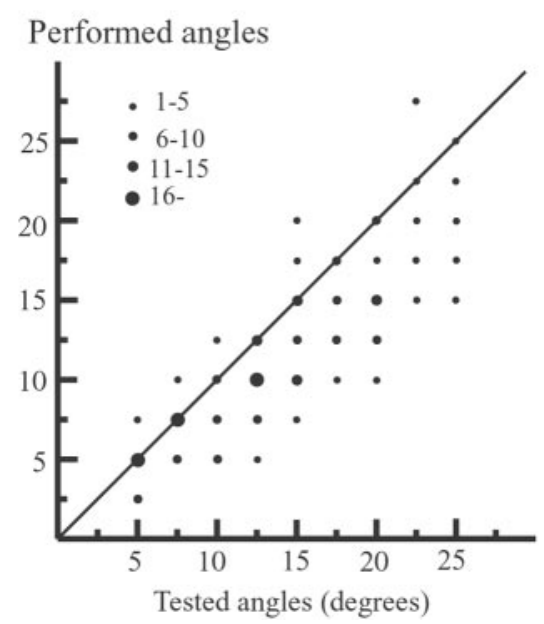

Figure 1. The position of the right wrist $(a)$ and angle evaluation task (b). $a$, The wrist was completely relaxed throughout the experiment and hung freely. We measured the wrist angles from the original position (represented by ang) with the aid of two small bars attached laterally to the surface of the skin over the wrist. In the psychophysical experiment, the subjects imagined palmar flexion or dorsiflexion of their right wrist during kinesthetic illusion of palmar flexion of the wrist (arrows). During PET scanning, the subjects passively felt illusory palmar flexion (illusion). The subjects imagined alternating continuous palmar and dorsiflexion (imagery). After each trial or scanning, the subjects replicated the experienced maximum angles of illusion by actually flexing their right wrist, and thus we could measure the angle of the illusory wrist flexion. $b$, Data points (filled circles) represent the number of trials performed at each angle tested. There is a significant correlation between perceived angles of the passively flexed wrist (Tested angles) and angles regenerated from them by voluntarily flexing the subject's own wrist (Performed angles).

the right wrist. In an imagery condition, the experimental setup was identical to that of the control condition, except that in the second vibration period the subjects had to imagine a slow movement of palmar flexion or dorsiflexion of the right wrist. Each condition was repeated five times in random order. No overt movements appeared during imagery. Analysis was done using the general linear model as implemented in the statistical software package SPSS (Version 10.0J, SPSS Japan Inc., Tokyo Japan).

\section{PET experiment}

Selection and training of subjects for the PET experiment. We selected 10 healthy right-handed men from another group, age 20-25 years, who experienced strong illusory palmar flexion with early onset (mean onset, $1.5 \mathrm{sec}$; mean illusory angle, $15^{\circ}$ ) and perceived no illusion when the right wrist was stimulated with a vibrator (Tanton EV258-A, Matsushita Electronics) at $12.5 \mathrm{~Hz}$ with an amplitude of $6 \mathrm{~mm}$. The subjects also had a high ability to control their imaginary body parts (CMI score $>7$ ). The subjects were trained to imagine slow wrist movements of alternating palmar flexion and dorsiflexion without producing any electromyogram 
a

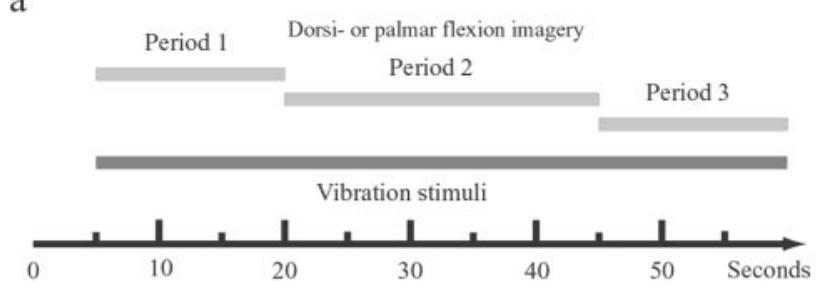

b

Illusory palmar flexion angle (degrees)

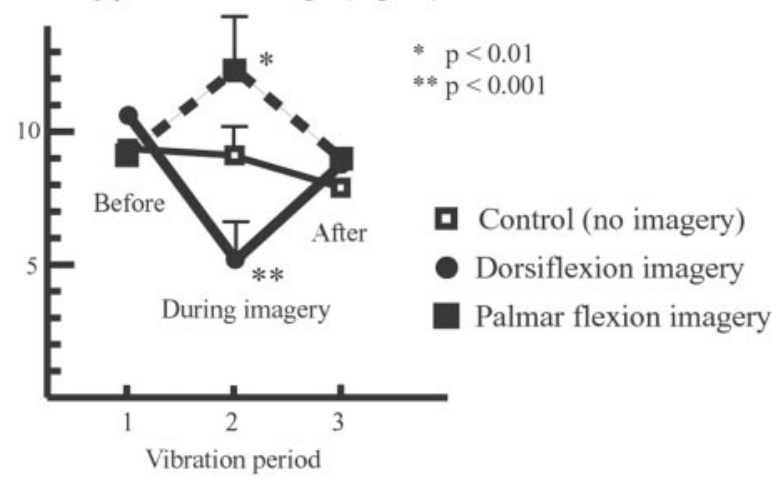

Figure 2. Task procedure (a) and results (b) of the psychophysical experiment. $a$, Kinesthetic illusions were elicited by vibration stimuli on the tendons of the right wrist extensor muscle in three separate periods for a total duration of $55.0 \mathrm{sec}$. Subjects imagined slow palmar flexion or dorsiflexion of the wrist only during the second period $(25.0 \mathrm{sec})$ of vibration. $b$, Directional influences of kinesthetic motor imagery on illusory palmar flexion. Kinesthetic motor imagery of palmar flexion enhanced (thick dark dashes) the angles of illusory palmar flexion, and imagery of dorsiflexion reduced (thick black line) the angles, when compared with the control condition. Error bars indicate SEMs.

(EMG) activity. The training was done $\sim 2$ weeks before the PET experiment.

EMG recording. The EMG was recorded from the surface of the skin over the wrist extensor represented by the extensor carpi ulnaris and wrist flexor (flexor carpi ulnaris) muscles. Electrodes were placed over the belly of the extensor and flexor muscles, and the EMG was sampled at $1 \mathrm{kHz}$. A high-cut filter was set at $3 \mathrm{kHz}$ and a low-cut filter at $1.5 \mathrm{~Hz}$. EMG recording began $\sim 30 \mathrm{sec}$ before bolus injection of a radioactive tracer (control period). The integrated EMG was calculated for each scanning period $(90 \mathrm{sec})$ and each control period. The integrated EMG value for the scanning period was divided by the value for the control period, and mean values were calculated from 30 trials for each PET condition.

Tasks. The experimental setup for PET was almost identical to that of the psychophysical experiment. The subject's head was fixed to the scanner bed with a headband, and eyes were covered and ears plugged. Each subject had 12 PET scans. The task consisted of four conditions, with three repetitions each. The task started just before the bolus injection of the radioactive tracer. The subjects were not allowed to say start or stop in the PET experiment and were encouraged to think of nothing in particular and not to move any body part. The order of conditions was balanced and randomized. The four conditions were "rest," "vibration," "illusion," and "imagery." For the rest condition, the subjects were instructed to relax completely. The vibrator was turned on to balance the humming of the vibrator across conditions but did not touch the subject's skin. For the vibration $(12.5 \mathrm{~Hz})$ and illusion $(83 \mathrm{~Hz})$ conditions, the subjects were instructed to focus their attention on the feeling coming from the right wrist and reminded of the requirement to report the angular velocities and maximum angles of any illusory movements. After each scan, subjects were asked whether they experienced illusory movements. After each illusion scan, the subjects were requested to replicate the illusory movement by actually moving the right wrist at the averaged illusory speed. The maximum angles and its movement time were mea- sured to estimate the angular velocity (maximum angles divided by its movement times). For the imagery condition, the subjects were required to imagine doing continuous alternating palmar flexion and dorsiflexion of the right wrist at the same speed as experienced in illusion without producing any EMG activity. The subjects were clearly instructed to mentally rehearse the wrist movements. The imagery condition always followed the illusion condition. After each illusion scan, as training, the subjects actually executed alternating palmar flexion and dorsiflexion of the right wrist at the same speed as the illusory movements by voluntary moving the right wrist. After this, they were also trained to imagine these movements without generating EMG activities.

PET scans. The PET scans were performed with a GE Advance tomograph (General Electric, Milwaukee, WI) with the interslice septa retracted (Sadato et al., 1997). The physical characteristics of this scanner have been described in detail elsewhere (De Grado et al., 1994; Lewellen et al., 1996). This scanner acquires 35 slices with an interslice spacing of $4.25 \mathrm{~mm}$. In the three-dimensional mode, the scanner acquires oblique sinograms with a maximum cross-coincidence of \pm 11 rings. A 10 min transmission scan with two rotating ${ }^{68} \mathrm{Ge} /{ }^{68} \mathrm{Ga}$ sources was performed for attenuation correction. CBF images were obtained by summing the activity during the $60 \mathrm{sec}$ period after the first detection of an increase in cerebral radioactivity after an intravenous bolus injection of $8 \mathrm{mCi}$ of ${ }^{15} \mathrm{O}$-labeled water (Sadato et al., 1997). The images were reconstructed with the Kinahan-Rogers reconstruction algorithm (Kinahan and Rogers, 1989). Hanning filters were used, giving transaxial and axial resolutions of 6 and $10 \mathrm{~mm}$ [full-width at half-maximum (FWHM)], respectively. The field of view and pixel size of the reconstructed images were 256 and $2 \mathrm{~mm}$, respectively. No arterial blood sampling was performed, and thus the images collected were those of tissue activity. Tissue activity recorded by this method is almost linearly related to rCBF (Fox et al., 1984; Fox and Mintun, 1989).

\section{Magnetic resonance imaging}

For anatomical reference, a high-resolution whole-brain magnetic resonance image for each subject was obtained separately, using a standard 1.5 Tesla magnetic resonance (MR) system (Horizon, General Electric). A regular head coil and a conventional T1-weighted, Fast Spoiled-Grass volume sequence with a flip angle of $30^{\circ}$, echo time of $5 \mathrm{msec}$, repetition time of $33 \mathrm{msec}$, and field of view of $24 \times 24 \mathrm{~cm}$ were used. A total of 124 transaxial images were obtained. The matrix size was $256 \times 256$, slice thickness was $1.5 \mathrm{~mm}$, and pixel size was $0.937 \times 0.937 \mathrm{~mm}$. Each high-resolution image was normalized to the template T1-weighted image that was already fitted to the standard stereotaxic space (Talairach and Tournoux, 1988). Because the cerebellar region is not well described in the Talairach's atlas, the anatomical localization of the activated areas in the cerebellum was performed using high-resolution magnetic resonance imaging (MRI) of the subjects of this study, according to Schmah-

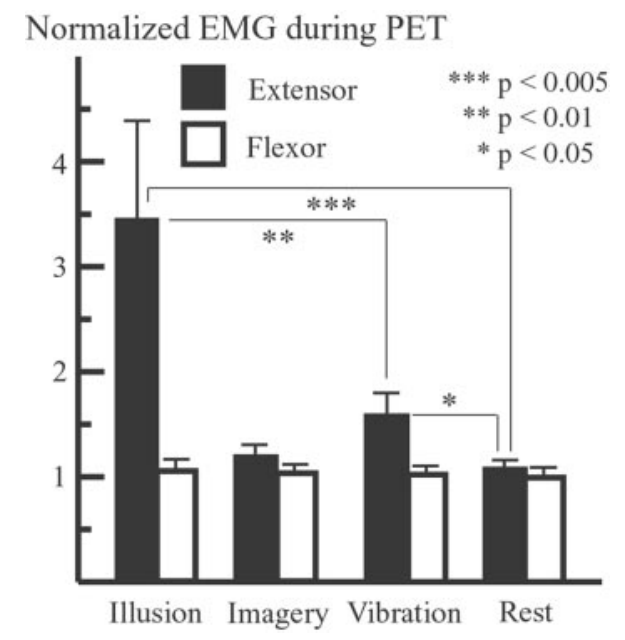

Figure 3. EMG activity during PET. There was no EMG activity in either the extensor muscles or the flexor muscles in the imagery condition, but activity significantly increased in the extensor muscles in the illusion and vibration conditions, when compared with the rest (control) condition. Error bars indicate SEMs. 


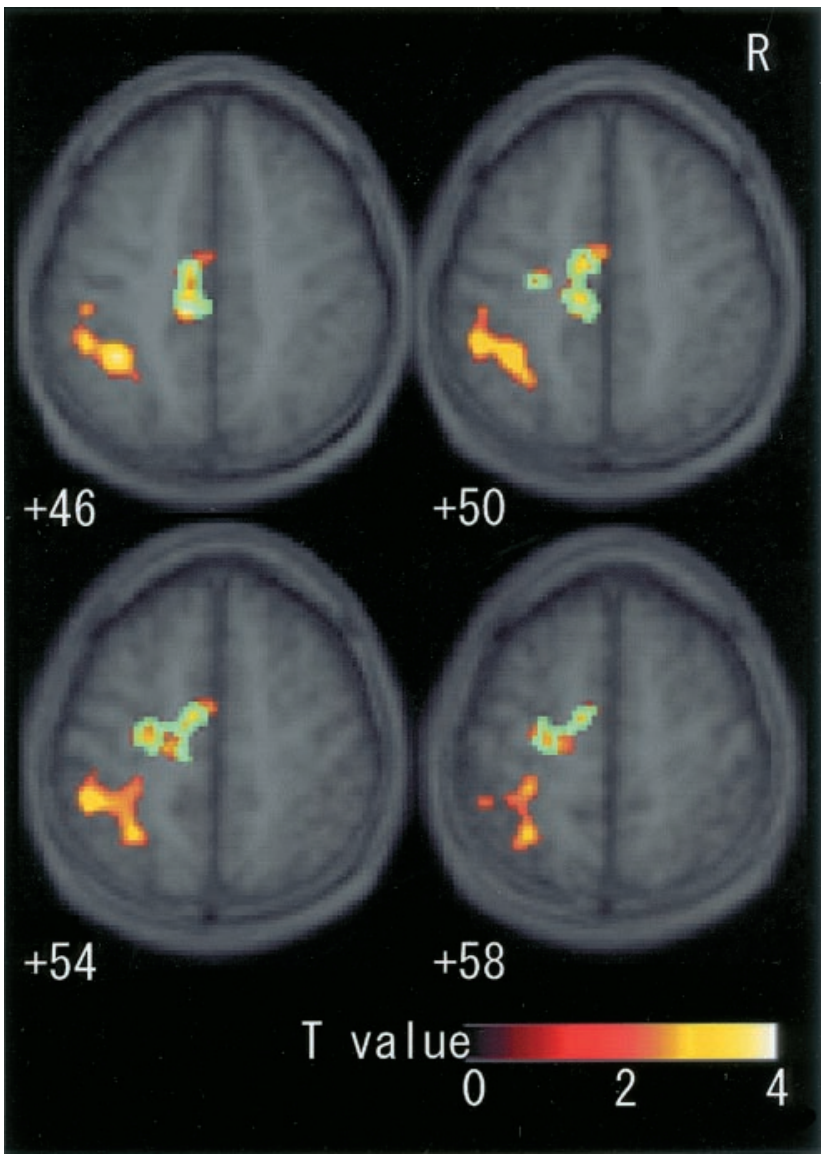

Figure 4. Fields activated by motor imagery in sections from $z+46$ to +58 superimposed on the mean MRI of all subjects. When imagery was contrasted with rest, clusters in the contralateral (left) CMA, SMA, PMD, and intraparietal sulcus area extending into postcentral sulcus were significantly activated. Blue areas were the identical sections that were also significantly activated as the common field [(imagery + illusion) vs (rest + vibration)]. $C M A$, Cingulate motor area; $S M A$, supplementary motor area; $P M D$, dorsal premotor cortex.

mann et al. (1999, 2000). We used the definitions of the functional areas (PMD, SMA, and CMA) in the cortical motor system, as defined by Roland and Zilles (1996).

\section{Analysis of CBF data}

The data on $\mathrm{CBF}$ were analyzed with statistical parametric mapping (SPM99, Wellcome Department of Cognitive Neurology, London, UK) implemented in Matlab 5.3 (Mathworks Inc., Sherborn, MA) (Friston et al., 1994, 1995a,b). The scans from each subject were realigned, with the first image used as a reference. This generated an aligned set of images per subject and a mean image. The structural T1-weighted magnetic resonance image was coregistered to this mean PET image. After this, the co-registered T1 image was normalized into a standard stereotaxic space involving linear and nonlinear three-dimensional transformations. The parameters from this normalization process were then applied to each PET image. The PET images were reformatted to isometric voxels $\left(2 \times 2 \times 2 \mathrm{~mm}^{3}\right)$. The normalized PET images were filtered with a Gaussian kernel of $10 \mathrm{~mm}$ (FWHM) in the $x, y$, and $z$ axes.

After the appropriate design matrix was specified, the effects of condition and subject were estimated according to the general linear model at each and every voxel. Mean signal changes over the whole brain were removed by proportional scaling. To test the hypothesis on regionally specific condition effects, the estimates were compared by means of linear contrasts. To depict the areas activated by the effect of motor imagery, contrast imagery versus rest was used, with statistical significance of $p<$ 0.01 corrected for multiple comparisons at cluster level over the entire volume in the brain analyzed. To identify the neural substrates commonly activated by the effect of imagery and that of illusion, the following procedure was performed. First, we used the contrasts (imagery + illusion) versus (rest + vibration) to test the significant spatial extent of active fields in the whole brain. The corrected $p$ values were also set at $p<0.01$. Within these cortical areas, we exclusively masked regions that were specific to the effect of illusion or that of imagery, as defined by the contrasts (illusion vs vibration) versus (imagery vs rest) or the contrasts (imagery vs rest) versus (illusion vs vibration). The threshold for the mask was $p<0.05$, uncorrected. Results of a conjunction analysis (Price and Friston, 1997) of (illusion vs vibration) and (imagery vs rest) ( $p<$ 0.0001 , uncorrected) showed the same activation patterns as the results of the present analysis.

After identification of the common areas, the mean percentage increase of PET data in illusion against rest was obtained from each region-of-interest in the primary sensory and motor cortices, CMA, SMA, PMD, and cerebellum. A region-of-interest was defined as a sphere with a $5 \mathrm{~mm}$ radius at the center of the peak voxel in each area. We calculated the correlation between mean percentage increase of PET data and the integrated amplitude of EMG activity in either the extensor or flexor muscles.

\section{RESULTS}

\section{Psychophysical experiment}

Subjects experienced illusory palmar flexion of the right wrist in the control condition (without motor imagery). This started $\sim 4$ sec after the onset of vibration and continued until the stimulus ended. When subjects imagined slow palmar flexion or dorsiflexion during vibration stimuli, the kinesthetic motor imagery significantly influenced the experienced illusory palmar flexion angles (Fig. 2b) in the absence of overt movements. Multi-way ANOVA showed significant interaction between conditions and vibration periods $\left(F_{(4,72)}=18.0 ; p<0.001\right)$. When subjects imagined slow wrist dorsiflexion, the perceptual illusory angle of palmar flexion was significantly reduced when compared with the control condition $(t=5.12$; df $=18 ; p<0.001)$ (Fig. 2b).

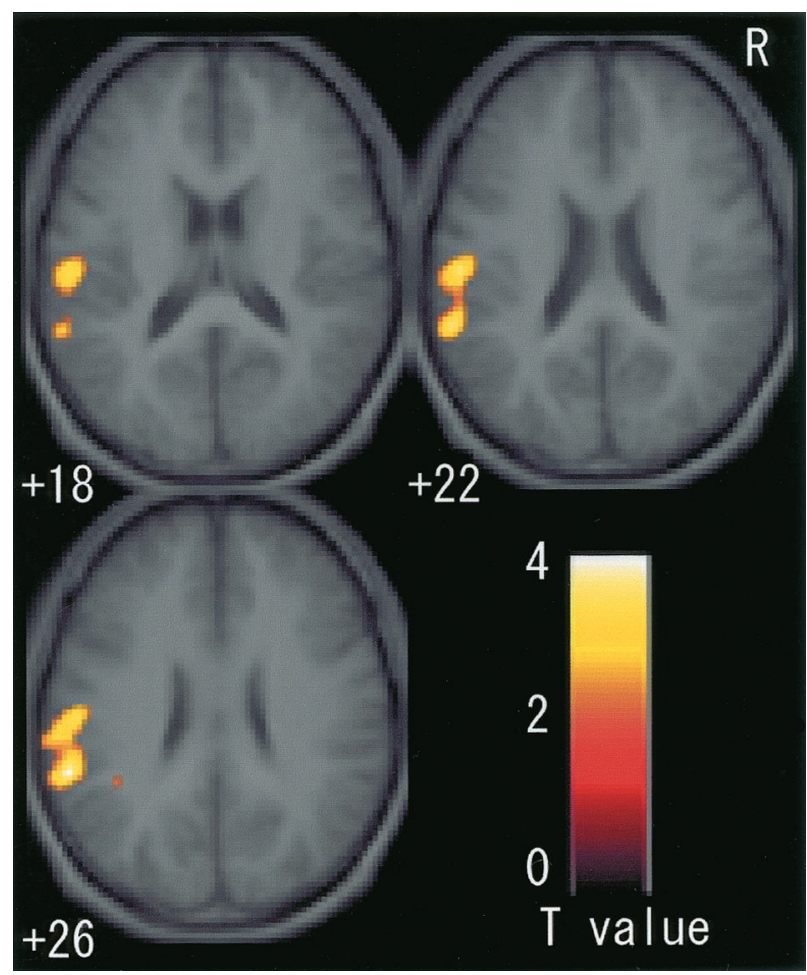

Figure 5. Fields activated by motor imagery in sections from $z+18$ to +26 . When imagery was contrasted with rest, the cluster in the left parietal operculum was significantly activated. There was no common active field active in this region. 
However, when subjects imagined palmar flexion, the perceptual illusory angle of palmar flexion was significantly enhanced $(t=$ 3.15; df $=18 ; p<0.01$ ) (Fig. $2 b$ ).

The effects of palmar motor imagery on the experienced illusory angles of palmar flexion were significantly correlated with the scores on the CMI test, which evaluates the ability to reconstruct imaginary body postures. The higher the score on the CMI test, the greater the motor imagery influenced the illusory experience $(r=0.67 ; n=19 ; p<0.01)$.

\section{Psychophysical features and EMG activity during PET}

All subjects experienced vivid illusory palmar flexion during PET scanning when the tendons of the right wrist extensor muscle were vibrated at $83 \mathrm{~Hz}$ (illusion), but they had no reliable illusions at $12.5 \mathrm{~Hz}$ (vibration). The mean value of experienced illusory maximum angles $(n=10)$ was $16.8^{\circ}$ (range, $\left.7.5-30^{\circ}\right)$. The mean angular velocity of illusory palmar flexion $(n=10)$ was $2.8^{\circ} / \mathrm{sec}$ (range, $1.2-9.3^{\circ} / \mathrm{sec}$ ). The vibration stimuli elicited no actual movement. No EMG activity was observed in either wrist extensors or wrist flexors during the imagery and rest (control) conditions. However, EMG activity significantly increased in the extensor muscles in the illusion and vibration conditions when compared with rest $(t=3.26$, df $=30, p<0.005 ; t=2.41$, df $=$ $30, p<0.05$ ) (Fig. 3), although it was still at a very low level (maximum, $\sim 14.8 \%$ that of actual wrist extension). There was no significant increase in EMG activity in the flexor muscles (agonistic muscles to illusory movement) in either the illusion or vibration conditions.

\section{Patterns of rCBF in the entire brain}

Fields activated by motor imagery (imagery versus rest)

When rCBF during the imagery condition was compared with rest, three significant clusters were activated. One cluster was located in the contralateral (left) CMA, extending rostrally into the SMA and dorsally into the dorsal PMD (Fig. 4). The second cluster was located in the parietal cortices and had two major peaks, one in the contralateral intraparietal sulcus area (Fig. 4) and another in the parietal operculum (Fig. 5). The former cluster extended into the postcentral sulcus area. The third cluster was located in the ipsilateral (right) cerebellum (Fig. 6). The cluster sizes and locations of the peak voxels in these active fields are summarized in Table 1.

\section{Fields commonly activated by motor imagery and kinesthetic} illusion (imagery + illusion vs rest + vibration)

Neural substrates commonly activated by both the imagery (imagery vs rest) and the illusion (illusion vs vibration) effects were the contralateral CMA, extending dorsally into the SMA and PMD, and the ipsilateral intermediate part of the cerebellum. Fifty-four percent of the CMA cluster and $25 \%$ of the cerebellum cluster in imagery versus rest were identical sections that were significantly activated as common fields (Figs. 4, 6). The cluster sizes and locations of the peak voxels in these active fields are summarized in Table 2.

\section{Fields activated by kinesthetic illusion (illusion vs vibration)}

In addition to the commonly active areas, the contralateral (left) SM1 was activated when illusion was contrasted with vibration. The mean percentage increase of rCBF for the illusion in the SM1 was not correlated with the integrated EMG activities in either the extensor $(r=-0.02)$ or flexor muscles $(r=-0.03)$.

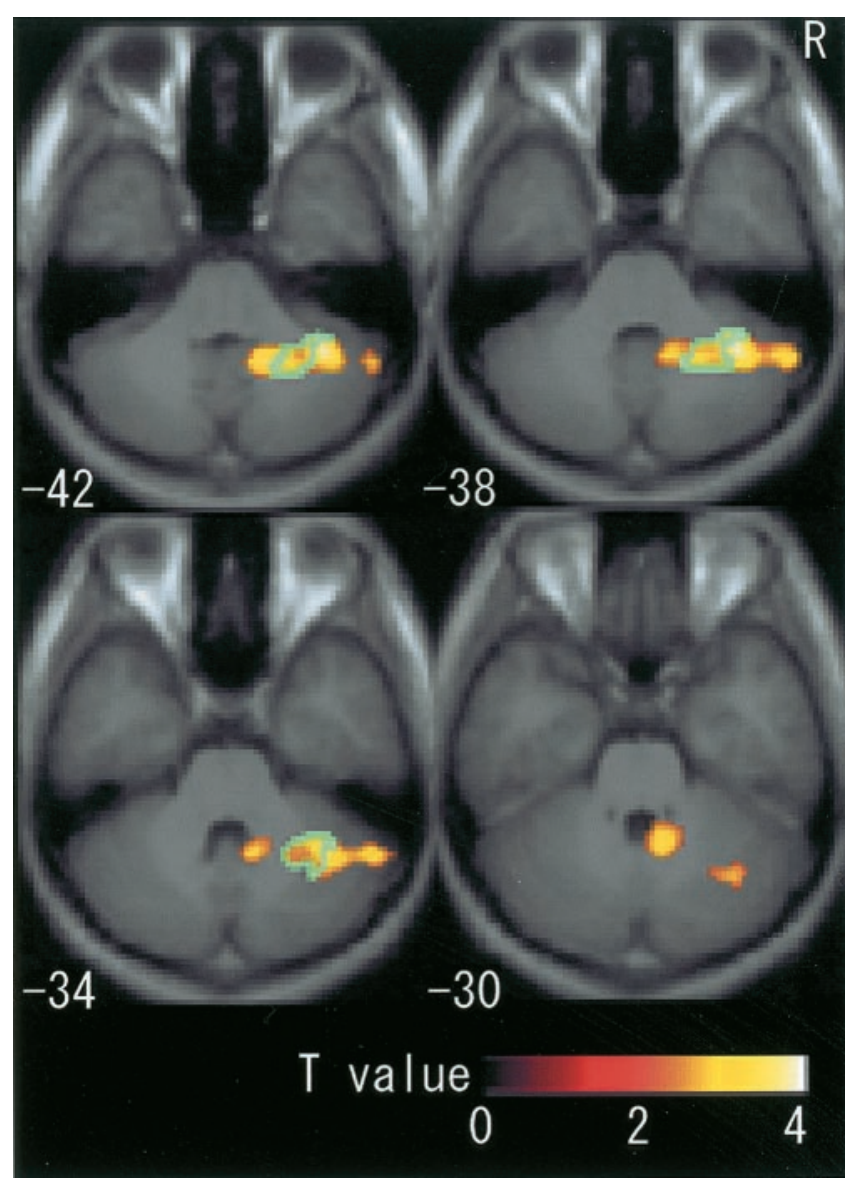

Figure 6. Fields activated by motor imagery in right cerebellum $(z-42$ to -30$)$. When imagery was contrasted with rest, the right cerebellum, presumably covering sections IV, Crus I, dentate nucleus, and lateral hemisphere, was activated. For the indication of blue areas, see Figure 4.

\section{DISCUSSION}

The psychophysical experiment showed that motor imagery of the right wrist movement influenced kinesthetic sensation of illusory wrist movement in the absence of overt movement. This result shows that motor imagery involves a sensory simulation process. As we hypothesized, the kinesthetic sensation during motor imagery had to be internally generated because it was elicited neither by actual movements nor by any peripheral input. Furthermore, motor imagery of palmar flexion enhanced illusory palmar angle, and dorsiflexion imagery reduced the angle (Fig. $2 b$ ). This result clearly excludes the possibility that motor imagery acted as an extra mental load that always reduces the illusory angle regardless of the directions of imagined movements. One may conclude that the internally simulated sensation during motor imagery was, most probably, the sensation expected when the wrist movement is actually executed.

The PET experiment provided a neurophysiological explanation for the psychophysical results. Fields in the left CMA, SMA, $\mathrm{PMD}$, and the right cerebellum were commonly shared by motor imagery and kinesthetic illusion of wrist movements (Figs. 4, 6). Eventually, the PET results, together with the psychophysical results, suggested that the kinesthetic sensation during mental simulation of movement (motor imagery) is an important factor in activating these motor-related areas. 


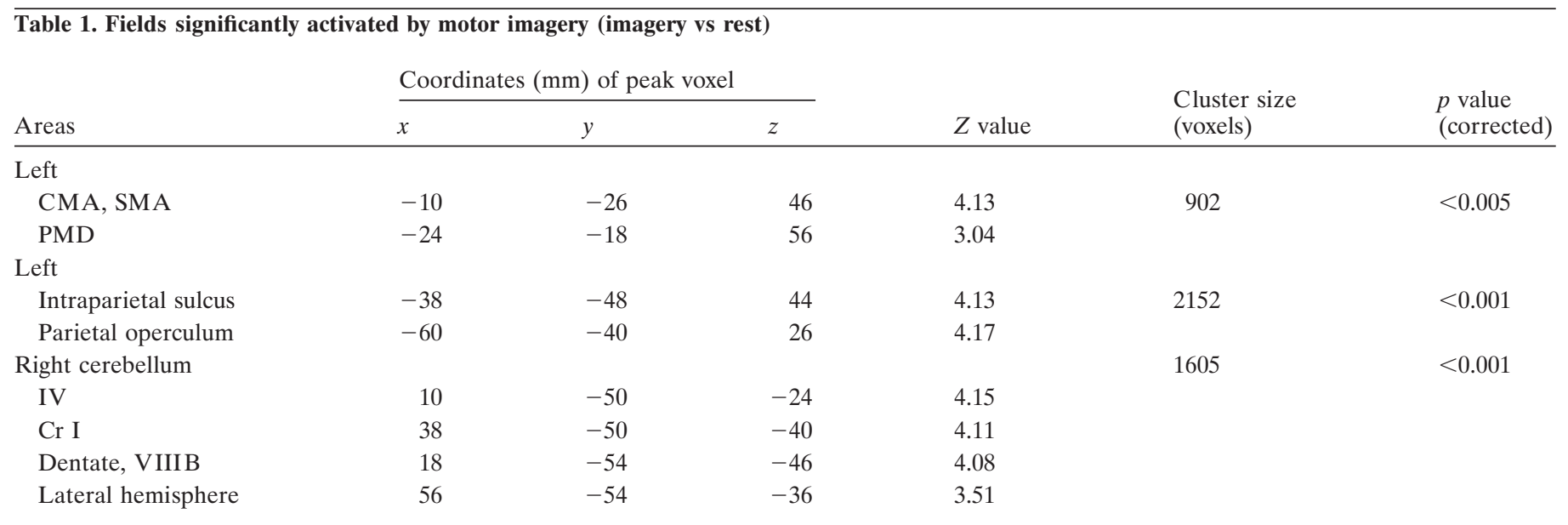

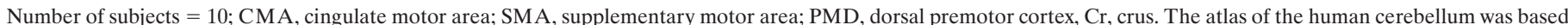

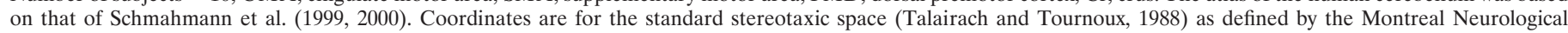
Institute.

\begin{tabular}{|c|c|c|c|c|c|c|}
\hline \multirow[b]{2}{*}{ Areas } & \multicolumn{3}{|c|}{$\underline{\text { Coordinates }(\mathrm{mm}) \text { of peak voxel }}$} & \multirow[b]{2}{*}{$Z$ value } & \multirow{2}{*}{$\begin{array}{l}\text { Cluster size } \\
\text { (voxels) }\end{array}$} & \multirow{2}{*}{$\begin{array}{l}p \text { value } \\
\text { (corrected) }\end{array}$} \\
\hline & $x$ & $y$ & $z$ & & & \\
\hline \multicolumn{7}{|l|}{ Left } \\
\hline CMA, SMA & -10 & -24 & 48 & 4.07 & 1279 & $<0.001$ \\
\hline PMD & -24 & -8 & 56 & 3.09 & & \\
\hline Right cerebellum & & & & & 801 & $<0.01$ \\
\hline Dentate & 24 & -56 & -40 & 4.41 & & \\
\hline VI & 32 & -44 & -40 & 4.09 & & \\
\hline
\end{tabular}

For abbreviations, see Table 1.

\section{Activation in the motor-related areas during motor imagery}

The motor imagery of right wrist movements (imagery vs rest) significantly activated the contralateral (left) CMA, SMA, PMD, parietal cortices, and ipsilateral cerebellum, which are normally engaged in the actual execution of wrist movements (Ehrsson et al., 2000). These areas were active in the absence of a significant increase in EMG activity in the related muscles (Fig. 3). It is somehow uncertain whether motor imagery of a given limb or body part activates its corresponding somatotopical sections in the motor areas. However, the present finding fits well with the notion that motor imagery is a neural process of mental rehearsal of a movement by activating motor-related areas, which are normally engaged in the actual movement (Jeannerod, 1994; Stephan et al., 1995; Jueptner et al., 1997; Luft et al., 1998; Jeannerod and Frak, 1999; Lotze et al., 1999; Binkofski et al., 2000; Gerardin et al., 2000).

We found activation only in the left motor areas during imagery, which are contralateral to the imagined wrist, whereas Gerardin et al. (2000) and Binkofski et al. (2000) demonstrated conspicuous bilateral cortical activations during motor imagery. However, the activation pattern shown by Binkofski et al. (2000), who used similar tasks as the present study, was also left dominant. This tendency might have been accentuated in the present study by less sensitivity of PET than functional MRI (fMRI) (Binkofski et al., 2000; Gerardin et al., 2000). The number of observations by PET is quite limited ( $\sim 10$ per subject); hence there is less statistical power to detect subtle changes of brain activity than with fMRI. Actually by lowering the threshold, involvement of the right hemisphere emerged in the present study.

We can exclude a possibility that the subjects visually imagined wrist movements in the present imagery task, because visually imagined finger movements predominantly activated prefrontal and parietal areas, but not the CMA, SMA, PMD, or cerebellum (Deiber et al., 1998). Indeed, prefrontal and parietal areas were predominantly active when the subjects imagined someone else performing a given action (third-person perspective) (Ruby and Decety, 2001). Also, lack of prefrontal activation in the present study may also be attributable to differences in the task performed. In this study, the subjects imagined self-controlled continuous wrist movements rather than externally paced motor imagery (Stephan et al., 1995; Lotze et al., 1999; Gerardin et al., 2000; Thobois et al., 2000). The subjects were clearly instructed to imagine doing the wrist movements at the same speed with experienced kinesthetic illusory movement $\left(2.8^{\circ} / \mathrm{sec}\right.$ on average across subjects; range, $\left.1.2-9.3^{\circ} / \mathrm{sec}\right)$. Thus, we assume that the subjects imagined doing the movements by accessing kinesthetic memory. Recent studies have shown that the memory retrieval process activates a sensory-specific (visual or auditory) cortex (Nyberg et al., 2000; Wheeler et al., 2000; Gandhi, 2001). Neural substrates involving the retrieval process of kinesthetic memory are unclear. However, the present study implies that motor areas could be associated with the process.

In the present study, we could not find any involvement of the SM1 in motor imagery. Because of the restricted spatial resolution of activation maps (PET data with spatial filtering of FWHM of $10 \mathrm{~mm}$ from a group of subjects), we cannot totally exclude the 
possibility that some of the activity observed in the PMD and postcentral sulcus area partly reflected activity from the adjacent SM1. However, no conspicuous cluster was observed on the central sulcus region ( $z$ coordinates from +46 to +58 ) (Fig. 4$)$, which was activated by actual wrist movements (Ehrsson et al., 2000) and by illusory wrist movements (Naito and Ehrsson, 2001). These two studies, together with Naito et al. (1999), showed the possible involvement of SM1 (most probably cytoarchitectonic areas $4 \mathrm{a}, 4 \mathrm{p}, 3 \mathrm{~b}$, and 1) in sensorimotor tasks when active fields overlapped with the central sulcus region. Indeed, involvement of SM1 in motor imagery of hand movement is not consistent between tasks performed (Thobois et al., 2000), and there is clear individual variability in SM1 involvement in motor imagery (Porro et al., 1996; Roth et al., 1996; Gerardin et al., 2000).

\section{Kinesthetic sensation and activation in the motor-related areas}

Activations in the contralateral (left) CMA, SMA, PMD, and ipsilateral (right) cerebellum were shared by motor imagery and kinesthetic illusion (Figs. 4, 6).

It has been shown that motor imagery activated the contralateral CMA, SMA, PMD (Roland et al., 1980; Stephan et al., 1995; Lotze et al., 1999; Binkofski et al., 2000; Gerardin et al., 2000; Thobois et al., 2000), and ipsilateral cerebellum (Decety et al., 1990; Jueptner et al., 1997; Luft et al., 1998; Lotze et al., 1999), and some of the shared active fields in the present study are consistent with previous studies in which illusory arm or wrist movements activated the contralateral CMA, SMA, and PMD (Naito et al., 1999; Naito and Ehrsson, 2001). Naito and Ehrsson (2001) showed that the contralateral cortical motor areas were specifically activated by the tendon vibration with illusion (83 $\mathrm{Hz}$ ). Frequency effects of vibration stimuli on the skin were found only in the sensory cortices but not in the motor areas (Harrington and Downs, 2001), and hence the present activations in the cortical motor areas represent kinesthetic illusion. A novel finding in the present study was the involvement of the intermediate part of ipsilateral cerebellum in kinesthetic illusion (Fig. 6). The cerebellum is believed to play an important role in human kinesthesia (Holmes, 1939; Grill et al., 1994; Haggard et al., 1994; Bastian et al., 1996). Actual wrist movements activate the anterior part of the ipsilateral cerebellum (Ehrsson et al., 2000). Passive arm movements also activate the human cerebellar hemisphere and vermis (Jueptner et al., 1997), whereas cells in the monkey intermediate cerebellum are recruited by passive movements of the upper limb (van Kan et al., 1993) and wrist (Bauswein et al., 1983).

The differences of activation patterns between kinesthetic illusion and motor imagery are the involvement of SM1 and parietal cortex. The SM1 was active only during illusion, whereas parietal cortex was activated only during imagery. Kinesthetic illusion is mainly elicited by the afferent inputs from the muscle spindles (Burke et al., 1976; Roll and Vedel, 1982; Roll et al., 1989), whereas there were no peripheral afferent inputs during motor imagery. The SM1 is the cortical target to receive the afferent inputs in non-human primates (Lemon et al., 1976; Fetz et al., 1980; Strick and Preston, 1982; Colebatch et al., 1990). The present activity of the SM1 during kinesthetic illusion may reflect the processing of the afferent inputs. This is corroborated with the finding that the mean percentage increase in PET data in the SM1 during illusion was not correlated with the integrated amplitude of EMG activity in either the extensor or flexor muscles. The subtle increase in EMG activity in the vibrated extensor muscles during illusion was most probably caused by neural circuits mediating the tonic vibration reflex in the spinal cord (Eklund and Hagbarth, 1966; Matthews, 1966) (Fig. 3). In contrast, the parietal cortices are known to generate mental movement representations (Sirigu et al., 1996; Gerardin et al., 2000). The subjects must internally program hand movements during motor imagery, whereas no intention of movement is required during kinesthetic illusion. Hence the parietal cortices were activated only during motor imagery.

It can be concluded that the shared motor fields are not exclusively activated by receiving muscle spindle afferent inputs, which mainly elicit kinesthetic illusion (Burke et al., 1976; Roll and Vedel, 1982; Gandevia, 1985; Roll et al., 1989; Collins and Prochazka, 1996), because motor imagery with no peripheral inputs or minimal inputs, if any (Kasai et al., 1997), also activated these motor areas. The self-controlled motor imagery (top-down information flow) and peripherally elicited kinesthetic illusion (bottom-up information flow) commonly reached the motor areas. This means that these motor areas may be activated by common functions shared by motor imagery and kinesthetic illusion. Because motor imagery psychophysically influenced the sensory experience of kinesthetic illusion, the activity in these motor areas may reflect experiencing the sensation of wrist movements.

There are several lines of evidence that motor areas participate in the sensory process. Passive arm movements activate the contralateral SMA (Weiller et al., 1996). Electrical microstimulation in certain sites within the human SMA and CMA causes various types of movement sensations in limbs in the absence of overt movements, regardless of the stimulus intensity (Fried et al., 1991; Lim et al., 1994).

The PET results, together with psychophysical results, are in agreement with the notion that "mental imagery reflects the effects of previous knowledge about the predicted sensory effects of the subject's own actions on sensory processing areas in the absence of sensory input" (Frith and Dolan, 1997). This view has been generally supported by studies of the visual imagery effect on visual areas (Kosslyn et al., 1995, 1997, 1999) and may also be true in motor imagery. However, in the case of motor imagery, internally simulated sensory experience of movement recruits multiple motor areas.

\section{REFERENCES}

Annett J (1996) On knowing how to do things: a theory of motor imagery. Cognit Brain Res 3:65-69.

Bastian AJ, Martin TA, Keating JG, Thach WT (1996) Cerebellar ataxia: abnormal control of interaction torques across multiple joints. J Neurophysiol 76:492-509.

Bauswein E, Kolb FP, Leimbeck B, Rubia FJ (1983) Simple and complex spike activity of cerebellar Purkinje cells during active and passive movements in the awake monkey. J Physiol (Lond) 339:379-394.

Binkofski F, Amunts K, Stephan KM, Posse S, Schormann T, Freund HJ, Zilles K, Seitz RJ (2000) Broca's region subserves imagery of motion: a combined cytoarchitectonic and fMRI study. Hum Brain Mapp 11:273-285.

Burke D, Hagbarth K, Lofstedt L, Wallin G (1976) The responses of human muscle spindle endings to vibration of non-contracting muscles. J Physiol (Lond) 261:673-693.

Clark FJ, Burgess RC, Chapin JW, Lipscomb WT (1985) Role of intramuscular receptors in the awareness of limb position. J Neurophysiol 54:1529-1540.

Colebatch JG, Sayer RJ, Porter R, White OB (1990) Responses of monkey precentral neurones to passive movements and phasic muscle stretch: relevance to man. Electroencephalogr Clin Neurophysiol 75:44-55.

Collins DF, Prochazka A (1996) Movement illusions evoked by ensemble cutaneous input from the dorsum of the human hand. J Physiol (Lond) 496:857-871. 
Craske B (1977) Perception of impossible limb positions induced by tendon vibration. Science 196:71-73.

Decety J, Sjoholm H, Ryding E, Stenberg G, Ingvar DH (1990) The cerebellum participates in mental activity: tomographic measurements of regional cerebral blood flow. Brain Res 535:313-317.

De Grado TR, Turkington TG, Williams JJ, Stearns CW, Hoffman JM (1994) Performance characteristics of a whole-body PET scanner. J Nucl Med 35:1398-1406.

Deiber M-P, Ibañez V, Honda M, Sadato N, Raman R, Hallett M (1998) Cerebral processes related to visuomotor imagery and generation of simple finger movements studied with positron emission tomography. NeuroImage 7:73-85.

Ehrsson HH, Naito E, Geyer S, Amunts K, Zilles K, Forssberg H, Roland PE (2000) Simultaneous movements of upper and lower limbs are coordinated by motor representations that are shared by both limbs: a PET study. Eur J Neurosci 12:3385-3398.

Eklund G, Hagbarth KE (1966) Normal variability of tonic vibration reflexes in man. Exp Neurol 16:80-92.

Feltz DL, Landers DM (1983) The effects of mental practice on motor skill learning and performance: a meta-analysis. Int J Sports Psychol 5:25-57.

Fetz EE, Finocchio DV, Baker MA, Soso MJ (1980) Sensory and motor responses of precentral cortex cells during comparable passive and active joint movements. J Neurophysiol 43:1070-1089.

Fox PT, Mintun MA (1989) Noninvasive functional brain mapping by change-distribution analysis of averaged PET images of $\mathrm{H}_{2}{ }^{15} \mathrm{O}$ tissue activity. J Nucl Med 30:141-149.

Fox PT, Mintun MA, Raichle ME, Herscovitch P (1984) A noninvasive approach to quantitative functional brain mapping with $\mathrm{H}_{2}{ }^{15} \mathrm{O}$ and positron emission tomography. J Cereb Blood Flow Metab 4:329-333.

Fried I, Katz A, McCarthy G, Sass KJ, Williamson P, Spencer SS, Spencer DD (1991) Functional organization of human supplementary motor cortex studied by electrical stimulation. J Neurosci 11:3656-3666

Friston KJ, Worsley KJ, Frackowiak RSJ, Mazziotta JC, Evans AC (1994) Assessing the significance of focal activations using their spatial extent. Hum Brain Mapp 1:210-220.

Friston KJ, Ashburner J, Frith CD, Heather JD, Frackowiak RSJ (1995a) Spatial registration and normalization of images. Hum Brain Mapp 2:165-188.

Friston KJ, Holmes AP, Worsley KJ, Poline JB, Frith CD, Frackowiak RSJ (1995b) Statistical parametric maps in functional imaging: a general linear approach. Hum Brain Mapp 2:189-210.

Frith C, Dolan RJ (1997) Brain mechanisms associated with top-down processes in perception. Philos Trans $\mathrm{R}$ Soc Lond B Biol Sci 352:1221-1230.

Gandevia SC (1985) Illusory movements produced by electrical stimulation of low-threshold muscle afferents from the hand. Brain 108:965-981.

Gandhi SP (2001) Memory retrieval: reactivating sensory cortex. Curr Biol 11:R32-R34.

Gerardin E, Sirigu A, Lehericy S, Poline JB, Gaymard B, Marsault C, Agid Y, Le Bihan D (2000) Partially overlapping neural networks for real and imagined hand movements. Cereb Cortex 10:1093-1104.

Goodwin GM, McCloskey DI, Matthews PBC (1972a) The contribution of muscle afferents to kinesthesia shown by vibration induced illusions of movement and by the effects of paralysing joint afferents. Brain 95:705-748.

Goodwin GM, McCloskey DI, Matthews PBC (1972b) Proprioceptive illusions induced by muscle vibration: contribution by muscle spindles to perception? Science 175:1382-1384.

Grill SE, Hallett M, Marcus C, McShane L (1994) Disturbances of kinaesthesia in patients with cerebellar disorders. Brain 117:1433-1447.

Haggard P, Jenner J, Wing A (1994) Coordination of aimed movements in a case of unilateral cerebellar damage. Neuropsychologia 32:827-846.

Harrington GS, Downs III JH (2001) FMRI mapping of the somatosensory cortex with vibratory stimuli. Is there a dependency on stimulus frequency? Brain Res 897:188-192.

Holmes G (1939) The cerebellum of man. Brain 62:1-30.

Jeannerod M (1994) The representing brain: neural correlates of motor intention and imagery. Behav Brain Sci 17:187-245.

Jeannerod M, Frak V (1999) Mental imaging of motor activity in human. Curr Opin Neurobiol 9:735-739.

Jueptner M, Ottinger S, Fellows SJ, Adamschewski J, Flerich L, Muller SP, Diener HC, Thilmann AF, Weiller C (1997) The relevance of sensory input for the cerebellar control of movements. NeuroImage 5:41-48.

Kasai T, Kawai S, Kawanishi M, Yahagi S (1997) Evidence for facilitation of motor evoked potentials (MEPs) induced by motor imagery. Brain Res 744:147-150.

Kinahan PE, Rogers JG (1989) Analytic three dimensional image reconstruction using all detected events. IEEE Trans Nucl Sci 36:964-968.

Kitada R, Naito E, Matsumura M (2002) Perceptual changes in illusory wrist flexion angles resulting from motor imagery of the same wrist movements. Neuroscience, in press.

Kosslyn SM, Thompson WL, Kim IJ, Alpert NM (1995) Topographical representations of mental images in primary visual cortex. Nature 378:496-498.

Kosslyn SM, Thompson WL, Alpert NM (1997) Neural systems shared by visual imagery and visual perception: a positron emission tomography study. NeuroImage 6:320-334.

Kosslyn SM, Pascual-Leone A, Felician O, Camposano S, Keenan JP, Thompson WL, Ganis G, Sukel KE, Alpert NM (1999) The role of area 17 in visual imagery: convergent evidence from PET and rTMS. Science 284:167-170.

Lemon RN, Hanby JA, Porter R (1976) Relationship between the activity of precentral neurones during active and passive movements in conscious monkeys. Proc R Soc Lond B Biol Sci 194:341-373.

Lewellen TK, Kohlmeyer SG, Miyaoka RS, Kaplan MS (1996) Investigation of the performance of the General Electric advance positron emission tomograph in 3D mode. IEEE Trans Nucl Sci 43:2199-2206.

Lim SH, Dinner DS, Pillay PK, Luder H, Morris HH, Klem G, Wyllie E, Awad IA (1994) Functional anatomy of the human supplementary sensorimotor area: results of extraoperative electrical stimulation. Electroencephalogr Clin Neurophysiol 91:179-193.

Lotze M, Montoya P, Erb M, Hulsmann E, Flor H, Klose U, Birbaumer N, Grodd W (1999) Activation of cortical and cerebellar motor areas during executed and imagined hand movements: an fMRI study. J Cognit Neurosci 11:491-501.

Luft AR, Skalej M, Stefanou A, Klose U, Voigt K (1998) Comparing motion- and imagery-related activation in the human cerebellum: a functional MRI study. Hum Brain Mapp 6:105-113.

Mahoney MJ, Avener M (1987) Psychology of the elite athlete. An explorative study. Cognit Ther Res 1:135-141.

Matthews PBC (1966) The reflex excitation of the soleus muscle of the decerebrate cat caused by vibration applied to its tendon. J Physiol (Lond) 184:450-472.

Naito E (1994) Controllability of motor imagery and transformation of visual imagery. Percept Mot Skills 78:479-487.

Naito E, Ehrsson HH (2001) Kinesthetic illusion of wrist movement activates motor-related areas. NeuroReport 12:3805-3809.

Naito E, Ehrsson HH, Geyer S, Zilles K, Roland PE (1999) Illusory arm movements activate cortical motor areas: a PET study. J Neurosci 19:6134-6144.

Nishida T, Katube A, Inomata K, Okazawa Y, Ito M, Kayama S, Tsuruhara K, Yoshizawa Y (1986) A new test for controllability of motor imagery: the examination of its validity and reliability. Jpn J Phys Ed $31: 13-22$.

Nyberg L, Habib R, McIntosh AR, Tulving E (2000) Reactivation of encoding-related brain activity during memory retrieval. Proc Natl Acad Sci USA 97:11120-11124.

Porro CA, Francescato MP, Cettolo V, Diamond ME, Baraldi P, Zuian C, Bazzocchi M, di Prampero PE (1996) Primary motor and sensory cortex activation during motor performance and motor imagery: a functional magnetic resonance imaging study. $\mathrm{J}$ Neurosci 16:7688-7698.

Price CJ, Friston KJ (1997) Cognitive conjunction: a new approach to brain activation experiments. NeuroImage 5:261-270.

Roland PE, Zilles K (1996) Functions and structures of the motor cortices in humans. Curr Opin Neurobiol 6:773-781.

Roland PE, Larsen B, Lassen NA, Skinhoj E (1980) Supplementary motor area and other cortical areas in organization of voluntary movements in man. J Neurophysiol 43:118-136.

Roll JP, Vedel JP (1982) Kinaesthetic role of muscle afferent in man, studied by tendon vibration and microneurography. Exp Brain Res 47:177-190.

Roll JP, Vedel JP, Ribot E (1989) Alteration of proprioceptive messages induced by tendon vibration in man: a microneurograpic study. Exp Brain Res 76:213-222.

Roth M, Decety J, Raybaudi M, Massarelli R, Delon-Martin C, Segebarth C, Morand S, Gemignani A, Decorps M, Jeannerod M (1996) Possible involvement of primary motor cortex in mentally simulated movement: a functional magnetic resonance imagining study. NeuroReport 17:1280-1284.

Ruby P, Decety J (2001) Effect of subjective perspective taking during simulation of action: a PET investigation of agency. Nat Neurosci 4:546-550.

Sadato N, Carson RE, Daube-Witherspoon ME, Campbell G, Hallett M, Herscovitch P (1997) Optimization of noninvasive activation studies with ${ }^{15} \mathrm{O}$-water and three-dimensional positron emission tomography. J Cereb Blood Flow Metab 17:732-739.

Schmahmann JD, Doyon J, McDonald D, Holmes C, Lavoie K, Hurwitz AS, Kabani N, Toga A, Evans A, Petrides M (1999) Threedimensional MRI atlas of the human cerebellum in proportional stereotaxic space. NeuroImage 10:233-260.

Schmahmann JD, Doyon J, Toga AW, Petrides M, Evans AC (2000) MRI atlas of the human cerebellum. San Diego: Academic.

Sirigu A, Duhamel JR, Cohen L, Pillon B, Dubois B, Agid Y (1996) The 
mental representation of hand movements after parietal cortex damage. Science 273:1564-1568.

Stephan KM, Fink GR, Passingham RE, Silbersweig D, Ceballos-Baum, Frith CD, Frackowiak RS (1995) Functional anatomy of the mental representation of upper extremity movements in healthy subjects. J Neurophysiol 73:373-386.

Strick PL, Preston JB (1982) Two representations of the hand in area 4 of a primate. II. Somatosensory input organization. J Neurophysiol 48:150-159.

Talairach J, Tournoux P (1988) A co-planar stereotaxic atlas of a human brain. New York: Thieme.
Thobois S, Dominey PF, Decety J, Pollak P, Gregoire MC, Le Bars D, Broussolle E (2000) Motor imagery in normal subjects and in asymmetrical Parkinson's disease. Neurology 55:996-1002.

van Kan PLE, Gibson AR, Houk JC (1993) Movement-related inputs to intermediate cerebellum of the monkey. J Neurophysiol 69:74-94.

Weiller C, Juptner M, Fellows S, Rijntjes M, Leonhardt G, Kiebel S, Muller S, Diener HC, Thilmann AF (1996) Brain representation of active and passive movements. NeuroImage 4:105-110.

Wheeler ME, Petersen SE, Buckner RL (2000) Memory's echo: vivid remembering reactivates sensory-specific cortex. Proc Natl Acad Sci USA 97:11125-11129. 